\title{
$\mathrm{Ni}$ 박막 위 $20 \mathrm{~nm}$ 급 고정렬 $\mathrm{Pt}$ 크로스-바 구조물의 형성 방법 박태완 ${ }^{1, \uparrow} \cdot$ 정현성 ${ }^{1, \uparrow} \cdot$ 조영래 ${ }^{2} \cdot$ 이정우 ${ }^{2, *} \cdot$ 박운익 ${ }^{1, *}$ \\ 1한국세라믹기술원 전자융합소재본부 \\ ${ }^{2}$ 부산대학교 재료공학부
}

\section{Pattern Formation of Highly Ordered Sub-20 nm Pt Cross-Bar on Ni Thin Film}

\author{
Tae Wan Park ${ }^{1, \dagger}$, Hyunsung Jung, ${ }^{1, \dagger}$, Young-Rae Cho ${ }^{2}$, Jung Woo Lee ${ }^{2, *}$, and Woon Ik Park, \\ ${ }^{1}$ Electronic Convergence Materials Division, Korea Institute of Ceramic Engineering \& Technology, Jinju 52851, Republic of Korea \\ ${ }^{2}$ Department of Materials Science and Engineering, Pusan National University, Pusan 46241, Republic of Korea
}

\begin{abstract}
Since catalyst technology is one of the promising technologies to improve the working performance of next generation energy and electronic devices, many efforts have been made to develop various catalysts with high efficiency at a low cost. However, there are remaining challenges to be resolved in order to use the suggested catalytic materials, such as platinum $(\mathrm{Pt})$, gold $(\mathrm{Au})$, and palladium $(\mathrm{Pd})$, due to their poor costeffectiveness for device applications. In this study, to overcome these challenges, we suggest a useful method to increase the surface area of a noble metal catalyst material, resulting in a reduction of the total amount of catalyst usage. By employing block copolymer (BCP) self-assembly and nano-transfer printing (n-TP) processes, we successfully fabricated sub-20 nm Pt line and cross-bar patterns. Furthermore, we obtained a highly ordered Pt cross-bar pattern on a Ni thin film and a Pt-embedded Ni thin film, which can be used as hetero hybrid alloy catalyst structure. For a detailed analysis of the hybrid catalytic material, we used scanning electron microscope (SEM), transmission electron microscope (TEM) and energy-dispersive X-ray spectroscopy (EDS), which revealed a well-defined nanoporous Pt nanostructure on the Ni thin film. Based on these results, we expect that the successful hybridization of various catalytic nanostructures can be extended to other material systems and devices in the near future.
\end{abstract}

(Received October 22, 2018; Accepted November 9, 2018)

Keywords: nanostructured materials, nano-transfer printing, catalyst, cross-bar nanostructure, nanostructural analysis

\section{1. 서 론}

촉매기술은 다양한 소자의 성능을 향상시키기 위한 핵심 기술로서, 배터리 [1-3]를 포함한 다양한 에너지 소자 [4-6] 와 가스센서 $[7,8]$ 를 포함한 각종 전기·전자소자 뿐만 아 니라 의학 [9], 바이오 분야 [10]에서도 많은 연구가 이루 어지고 있다. 또한, 전 세계적으로 친환경 에너지 기술의 중요성이 강조됨에 따라 에너지 저장 소자 [11], 자동차 배터리 [12], 연료전지 $[13,14]$ 등의 분야에서 촉매기술을 이

These authors contributed equally to this work. -박태완·정현성·박운익: 연구원, 조영래·이정우: 교수 *Corresponding Author: Jung Woo Lee [Tel: +82-51-510-2898, E-mail: jungwoolee@pusan.ac.kr] *Corresponding Author: Woon Ik Park [Tel: +82-55-792-2671, E-mail: thane0428@kicet.re.kr] Copyright (c) The Korean Institute of Metals and Materials
용하여 에너지 소비를 줄이고, 소자의 효율을 극대화하고 자 하는 연구가 활발하게 진행되고 있다.

대표적인 촉매 물질들 중, 백금 $(\mathrm{Pt})$, 금 $(\mathrm{Au})$, 팔라듐 (Pd) 등의 귀금속 물질은 소자의 효율을 높이기 위해 사용 되는 가장 우수한 소재로 여겨진다. 그러나 이들은 값이 비싸서 모든 양산화 제품에 적용시키기 어렵다는 치명적인 단점이 있다. 따라서, 최근 이를 극복하기 위하여 귀금속의 사용을 줄이고 효율은 극대화하기 위한 많은 노력들이 이 루어지고 있다 [15]. 특히, 촉매 역할을 하는 소재를 다공 성 구조로 제작하여 표면적을 극대화하거나 비교적 저렴한 비귀금속 소재와 혼합하여 합금으로 만드는 연구들이 대표 적이다 $[16,17]$. 하지만, 고정렬성을 갖는 다공성 나노소재 의 제조에 있어서, 그 크기를 5-50 nm 크기로 제어하는 것은 매우 힘이 든다. 
(a)
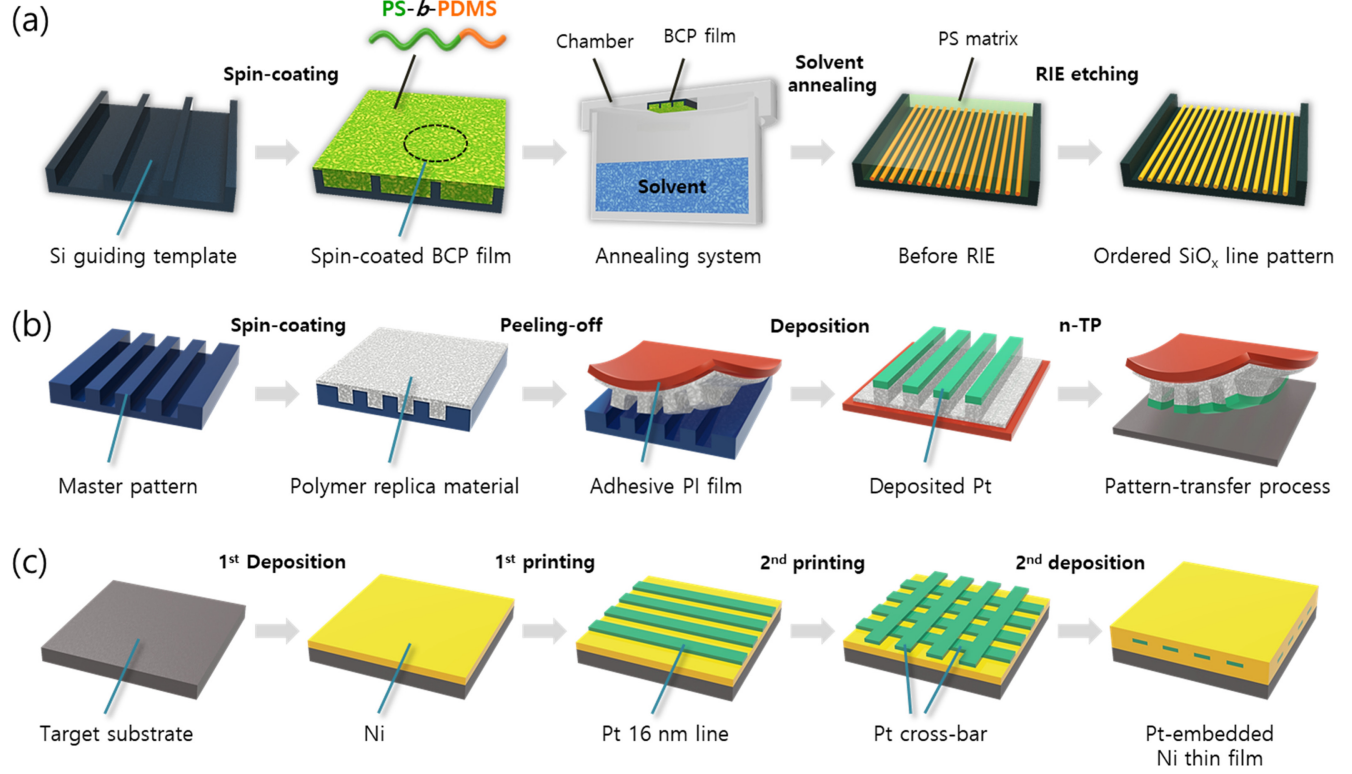

Fig. 1. Procedure of the formation of Pt-embedded Ni structure. (a) Process of sub- $20 \mathrm{~nm}$ self-assembled $\mathrm{SiO}_{\mathrm{x}}$ guiding template based on BCP self-assembly. (b) Nanotransfer printing process (replication of PMMA pattern and transfer-printing). (c) Formation of Pt-Ni hybrid nanopattern by two-step nanotransfer printing process and deposition.

본 연구에서는, 촉매 소재의 비표면적은 증가시키고 전 체 사용량은 줄일 수 있는 방법을 제시하기 위해, $\mathrm{Ni}$ 박 막 위에 약 $16 \mathrm{~nm}$ 크기의 선폭을 갖는 3 차원 $(3 \mathrm{D}$, three-dimensional) 다공성 Pt 나노구조물을 형성하고 해당 구조물에 대한 전자현미경 분석을 실시하였다. 우선, 정렬 성이 매우 높은 초미세 나노구조물 형성을 위해, 블록공중 합체 자기조립 공정으로 초미세 $\mathrm{SiO}_{\mathrm{x}}$ 라인 패턴의 템플릿 을 제작하였다. 해당 템플릿을 사용하여, 패턴전사 프린팅 공정으로 약 $16 \mathrm{~nm}$ 선폭을 갖는 $\mathrm{Pt}$ 크로스-바 패턴을 형 성하였고, 이 구조물 형성을 $\mathrm{Ni}$ 박막 상에 성공적으로 구 현하였다. 마지막으로, 본 구조물에 대한 상세한 분석을 위 해 주사전자현미경 (SEM), 투과전자현미경 (TEM), 그리고 에너지분산형 분광분석법 (EDS)을 이용하였고, 해당 나노 패턴의 구조와 성분을 분석하였다.

\section{2. 실험 방법}

\section{1. 초미세 나노 패턴의 구현을 위한 $\mathrm{BCP}$ 템플릿 제작}

그림 1. (a)는 초미세 나노 패턴을 형성하기 위해 사용 될 20 나노급 템플릿의 제작 과정을 나타낸 순서도이다. 우 선, 트렌치 (Trench) 영역의 폭이 1 um인 $\mathrm{Si}$ 템플릿 위에, 톨루엔 (Toluene)에 용해된 Poly(styrene- $b$-dimethylsiloxane) (PS- $b$-PDMS) 블록공중합고분자 (SD45, 분자량, $\mathrm{MW}=$
$45 \mathrm{~kg} / \mathrm{mol}$, PDMS부피분율, $\left.f_{\mathrm{PDMS}}=33 \%\right) 1.0 \mathrm{wt} \%$ 용액을 스핀코팅 하였다. 그리고 스핀코팅된 $\mathrm{SD} 45 \mathrm{BCP}$ 박막을 어닐링하기 위하여, 챔버의 상단부에 고정하였다. 챔버의 용량은 $25 \mathrm{ml}$ 이며, 챔버 내에 톨루엔 용액 $20 \mathrm{ml}$ 를 채우고 18시간 동안 용매어닐링 (Solvent vapor annealing)을 진 행하여 용매가 충분히 $\mathrm{SD} 45 \mathrm{BCP}$ 박막 내에 주입되도록 하였다. 어닐링 공정 후, Reactive Ion Etching (RIE) 장 비를 이용하여 플라즈마 처리를 하였는데, 미세상분리된 $\mathrm{BCP}$ 박막의 상단부에 형성되어 있는 PDMS 층을 제거하 고, PS matrix를 제거하기 위하여 각각 $\mathrm{CF}_{4}(50 \mathrm{~W}, 23 \mathrm{~s})$ 와 $\mathrm{O}_{2}(60 \mathrm{~W}, 35 \mathrm{~s})$ 플라즈마 에칭 공정을 진행하였다. 에 칭 공정 중, $\mathrm{O}_{2}$ 플라즈마를 통해 $\mathrm{PDMS}$ 내 $\mathrm{Si}$ 성분이 산화되면서 최종적으로 $16 \mathrm{~nm}$ 선폭 및 선 간격을 갖는 고 정렬성의 $\mathrm{SiO}_{\mathrm{x}}$ 라인 패턴을 제작할 수 있었다.

\section{2. $20 \mathrm{~nm}$ 급 선폭을 갖는 Pt 크로스-바 패턴의 제작}

그림 1 (b)는 고정렬성을 갖는 기능성 소재를 형성하는 패턴전사프린팅 공정 순서도이다. 우선, 그림 1 (a)의 공정 으로 만들어진 선폭 및 선 간격이 $16 \mathrm{~nm}$ 인 템플릿에 120 $\mathrm{kg} / \mathrm{mol}$ 의 분자량을 갖는 poly(methyl methacrylate) (PMMA)를 $5000 \mathrm{rpm}$ 의 회전속도로 17 초 동안 스핀코팅 하였다. 스핀코팅은 고체 상태로 존재하는 PMMA를 아세 톤 (Acetone), 톨루엔 (Toluene)을 1:1로 혼합한 용액에 $3.5 \mathrm{wt} \%$ 로 녹인 용액으로 진행하였다. 코팅된 PMMA 박 
막을 접착력이 존재하는 폴리이미드 (Polyimide, PI) 테이 프로 접착 및 탈착함으로써 템플릿과 역상을 나타내는 PDMS 복제패턴을 만들었고, 복제패턴 위 스퍼터링 공정 을 통하여 $\mathrm{Pt}$ 소재를 증착하였다. 스퍼터링 증착 공정 시 에는, 메인 챔버 내 기저 압력을 $3 \times 10^{-6}$ torr 이하로 유지 하였고, 증착이 이루어지는 순간에는 초고순도 $\mathrm{Ar}$ 가스를 주입하여 $5 \times 10^{-3}$ Torr의 작업 진공 환경을 만들어 준 다음 $\mathrm{DC}$ power $250 \mathrm{~W}$ 를 인가하였다. 복제패턴의 돌출된 상단 부에만 선택적으로 $\mathrm{Pt}$ 소재를 형성하기 위해 $\mathrm{Pt}$ 타겟과 복 제패턴을 약 $50-60^{\circ}$ 의 각도로 바라보게 하였다. 그 이유는, 라인 패턴이 형성되기 위해서는 전사될 (증착된) 영역과 전 사될 영역의 사이 (증착이 되지 않은) 공간이 존재해야 패 턴의 이동 전사가 용이하기 때문이다. 폴리머 복제패턴 위 형성된 $\mathrm{Pt}$ 를 전사하기 위해, 아세톤과 톨루엔이 $1: 1$ 로 혼 합된 용액에 노출하는 용매 어닐링 공정을 진행하였고, 용 액이 주입되어 부풀어진 복제패턴 (Pt/PMMA)을 $\mathrm{SiO}_{2} / \mathrm{Si}$ 대상기판 위 부착하여 손을 이용하여 압력을 가해주었다. 마지막으로, 접착성 PI 테이프를 제거하고 PMMA 복제 폴리머 패턴을 톨루엔으로 씻어내어 선폭이 약 $16 \mathrm{~nm}$ 인 $\mathrm{Pt}$ 라인 패턴을 형성하였다. 다공성의 $\mathrm{Pt}$ 크로스-바 패턴의 경우, 해당 공정을 두 번 반복함으로써 얻을 수 있었다.

\subsection{Ni-Pt 이종금속 하이브리드 나노구조체의 형성 및 구조분석}

그림 1 (c)는 Ni-Pt 이종 합금 하이브리드 나노구조물의 제작 과정이다. 먼저, 준비한 $\mathrm{SiO}_{2} / \mathrm{Si}$ 기판 상에 $\mathrm{Ni}$ 을 물 리적 증착 방법을 이용하여 형성하고, 물리증착된 $\mathrm{Ni}$ 박막 위에 패턴전사 프린팅 공정을 이용하여 $\mathrm{Pt} 16 \mathrm{~nm}$ 라인 패턴을 형성할 수 있다. 이를 3차원 계층적 다공성 구조물 로 만들기 위하여, 두 차례의 패턴전사 프린팅 공정을 진 행하고, 두 번 째의 프린팅은 일차적으로 프린팅된 나노 라인구조물에 대하여 $90^{\circ}$ 각도를 갖도록 실시한다. $\mathrm{Ni}$ 박 막 위에 Pt 크로스-바 나노구조물이 제대로 형성되었는지 여부와 구조 그리고 성분에 대한 형성을 확인하기 위하여, $\mathrm{TEM}$ 분석을 실시하고자 한다. 이 때, TEM 분석을 위하 여, $\mathrm{Ni}$ 을 한 번 더 증착하면 최종적으로 $\mathrm{Pt}$ 크로스-바 패 턴이 내재된 $\mathrm{Ni}$ 박막 구조를 얻을 수 있으며, 해당 Ni-Pt$\mathrm{Ni}$ 이종소재로 이루어진 하이브리드 나노구조물의 형상은 $\mathrm{SEM}, \mathrm{TEM}$, 그리고 $\mathrm{EDS}$ 분석을 통하여 확인하고자 한다.

\section{3. 결과 및 고찰}

본 연구에서는, 촉매 소재의 새로운 구조를 제시하기 위
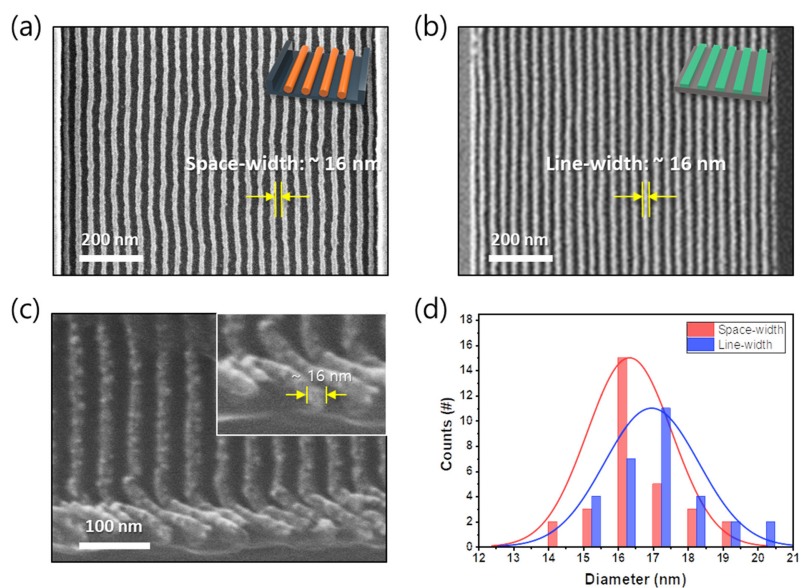

Fig. 2. Pattern formation of highly-ordered Pt line nanostructure by nanotransfer printing. (a) Self-assembled $\mathrm{SiO}_{\mathrm{x}}$ line structure obtained by cylinder-forming PS- $b$-PDMS BCP. (b) Transferprinted $\mathrm{Pt}$ line pattern with a width of $\sim 16 \mathrm{~nm}$ using a $\mathrm{SiO}_{\mathrm{x}}$ line pattern as a template. (c) Magnified SEM tilt-image of (b). (d) Distribution of sub-20 nm SiO ${ }_{\mathrm{x}}$ space-width and Pt line-width.

해 $\mathrm{Ni}$ 박막 위 $\mathrm{Pt}$ 크로스-바 패턴을 형성하고, 그 구조체 가 잘 형성되었는지를 확인하고자 하였다. 구체적으로는, 블록공중합체 자기조립 현상을 통해 초미세 나노 구조 템 플릿을 만들었고, 해당 템플릿을 사용하여 패턴전사 프린 팅 공정을 통해 $\mathrm{Ni}$ 박막 상에 $3 \mathrm{D}$ 다공성 구조인 $\mathrm{Pt} 16$ $\mathrm{nm}$ 크로스-바 패턴을 형성하였다. 그리고 그 구조물에 대 한 구조분석을 실시하였다.

먼저, 블록공중합체 자기조립 공정으로 초기 템플릿을 제 작하였다. 그림 2 (a)는 PS- $b$-PDMS 블록공중합체의, 용매 어닐링 공정 진행한 후의 SEM 이미지이며, $16 \mathrm{~nm}$ 선폭 및 선 간격을 갖는 정렬성이 우수한 $\mathrm{SiO}_{\mathrm{x}}$ 라인 구조가 형 성되었음을 확인하였다. 해당 구조물을 템플릿으로 활용하 여 패턴전사 프린팅 공정을 진행하였고, 프린팅된 $16 \mathrm{~nm}$ $\mathrm{Pt}$ 라인 패턴의 표면 (그림 2 (b))과 기울인 단면 (그림 2 (c))의 현미경 분석 결과, 높은 정렬도를 나타내는 패턴이 전사되었음을 확인할 수 있었다. 즉, 잘 정렬된 $\mathrm{SiO}_{\mathrm{x}}$ 라인 사이 공간의 폭에서 비롯된 초미세 패턴이 그림 2. (b)로 구현되었음을 알 수 있다. 보다 높은 정확성을 검증하기 위하여 그림 2 (a)의 공간 폭과 그림 2 (b)의 선폭을 각 각 30 부분에 대하여 크기를 측정해보았다 (그림 2 (d)). 그 결과, 정렬된 템플릿의 패턴 사이 간격의 평균과 표준 편차는 $16.33 \mathrm{~nm}, 1.21 \mathrm{~nm}$ 로 측정되었고, 전사된 $\mathrm{Pt}$ 라인 패턴의 평균값과 표준편차는 $16.97 \mathrm{~nm}, 1.35 \mathrm{~nm}$ 로 오차 범위 $4 \%$ 미만의 매우 정교하고 정렬도가 높은 패턴이 형 성되었음을 확인할 수 있었다.

성공적으로 형성된 $\mathrm{Pt}$ 라인 패턴을 기반으로 하여, $90^{\circ}$ 
(a)

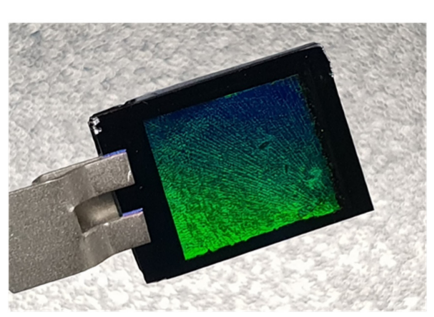

(b)

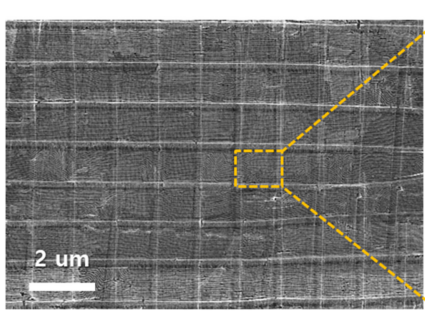

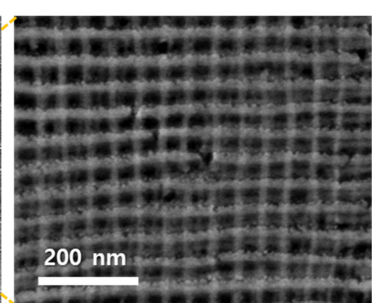

Fig. 3. Well-ordered Pt cross-bar pattern by 2-step nanotransfer printing. (a) Photo image of transfer-printed Pt cross-bar nanostructure. (b) SEM image of 3D-stacked Pt cross-bar pattern.

(a)

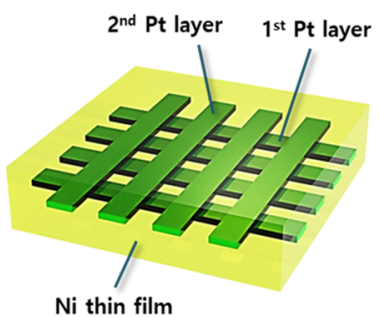

(d)

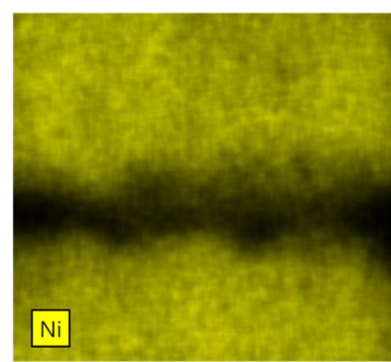

(b)

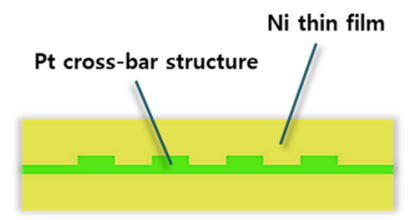

$<$ Cross-section view $>$

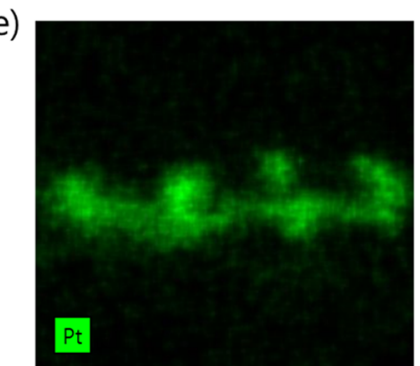

(c)

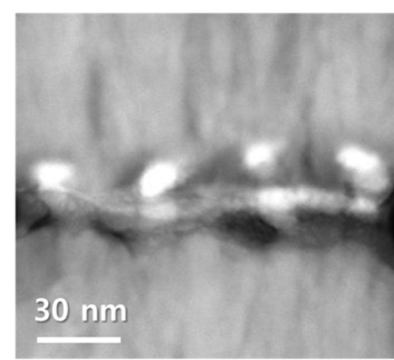

(f)

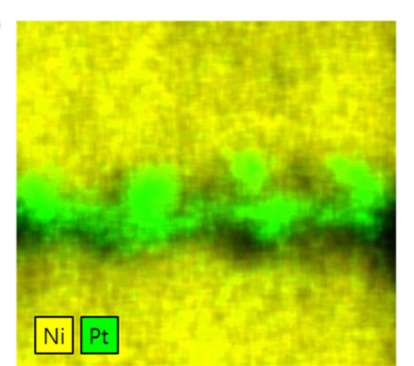

Fig. 4. Encapsulated Pt cross-bar pattern between Ni thin films. (a) 3D drawing image and (b) cross-section view of the Ni-Pt hybrid nanostructure. (c) Dark-field TEM image of hybrid Ni/Pt cross-bar/Ni film. EDS mapping image of (d) Ni, (e) Pt, and (f) Ni, Pt.

각도로 2회 프린팅 함으로써 고정렬성의 $\mathrm{Pt}$ 크로스-바 적 층형 3차원 나노구조물을 제작하였다. 그림 3 (a)는 Pt 크 로스-바 패턴이 프린팅되어 있는 기판의 실제 사진 이미지 이며, 그림 3 (b)는 해당 패턴의 SEM 이미지 결과물이다. 프린팅된 3차원 다공성 구조물이 전반적으로 잘 형성되어 있음을 확인할 수 있다.

그림 4는 $\mathrm{Ni}$ 박막 위 형성된 초미세 다공성 $\mathrm{Pt}$ 크로스바 (각 층의 라인 선폭: $16 \mathrm{~nm}$ ) 패턴의 구조분석 결과이다. 그림 4 (a)는 Ni-Pt 하이브리드 나노구조물의 3차원 그림, 그림 4 (b)는 2차원 단면 그림이다. 이러한 나노 다공소재 는 매우 미세하므로, 나노구조물의 성분과 기판과의 접촉 에 대한 분석은 SEM-EDS로 쉽지 않기 때문에, TEM을 통한 미세 구조물 단면 분석 및 $\mathrm{EDS}$ 성분 분석을 진행하 였다. 해당 하이브리드 나노구조물을 $\mathrm{TEM}$ 으로 분석한 결 과 (그림 4 (c)), $\mathrm{Ni}$ 박막 위 $\mathrm{Pt} 16 \mathrm{~nm}$ 라인 패턴의 적
층 구조가 잘 형성되어 있음을 확인할 수 있다. 이와 같은 결과를 더욱 면밀하게 분석하기 위해 EDS mapping을 실 시하였는데, $\mathrm{Ni}$ (그림 4 (b)), Pt (그림 4 (c)), 그리고 $\mathrm{Ni}-\mathrm{Pt}$ (그림 4 (d))의 성분분석 결과를 통해, $\mathrm{Ni}$ 박막 위 $\mathrm{Pt}$ 크로스-바 패턴이 성공적으로 형성되어 있음을 한 번 더 확인하였다. 결론적으로, 그림 4는 여러 차례의 패턴전사 프린팅을 통하여, 비표면적이 매우 큰 Ni-Pt 이종 금속 소 재 하이브리드 다공성 나노구조체의 제작이 가능하다는 사 실을 보여준다.

본 연구의 결과는, 패턴전사 프린팅 공정을 통하여 $\mathrm{Ni}$ 박막 위에 $20 \mathrm{~nm}$ 급 $\mathrm{Pt}$ 나노다공소재의 형성이 가능하고, 해당 구조물에 대하여 Photo, SEM, TEM, 그리고 EDS 분석을 진행하여 다각도에서 구조물을 분석하였으며, 소재 에 대한 분석 결과 또한 포함한다. 이러한 결과는, 값비싼 촉매 소재인 $\mathrm{Pt}$ 의 사용량을 줄이고 비표면적은 증가시키는 
나노구조물의 3 차원 적층화 및 다중소재의 하이브리드화 공정 기술이며, 새롭고 다양한 이종 또는 다중 촉매 소재 구현에 널리 활용될 것으로 기대된다. 특히, 해당 구조물은 다양한 에너지 및 전자 소자에 응용이 가능하며, 후속 관 련 응용연구가 이루어질 필요가 있다고 생각된다.

\section{4. 결 론}

본 연구에서는, 각종 에너지 및 전기-전자 소자의 촉매 로 사용되는 값비싼 귀금속 소재의 사용량을 줄이기 위하 여, 촉매 소재의 비표면적을 효과적으로 향상시킬 수 있는 $20 \mathrm{~nm}$ 급 다공성 하이브리드 촉매형성기술을 제시하고, 형 성된 나노구조와 그 성분에 대한 분석 결과를 보여주고자 한다. 우선, 블록공중합체 자기조립 현상을 이용하여 템플 릿으로 사용될 $16 \mathrm{~nm}$ 의 선폭을 갖는 고정렬성의 $\mathrm{SiOx}$ 라 인 패턴을 제작하였다. $16 \mathrm{~nm}$ 나노템플릿을 이용하여 초미 세 PMMA 복제패턴을 만들었고, 촉매소재인 $\mathrm{Pt}$ 를 증착하 여 원하는 기판으로 전사하였다. 해당 공정을 활용하여 $\mathrm{Pt}$ 다공성 크로스-바 구조체를 $\mathrm{Ni}$ 박막 위에 형성하였으며, $\mathrm{TEM}$ 및 $\mathrm{EDS}$ 분석을 실시하였다. 그 결과, $\mathrm{Ni} / \mathrm{Pt}$ 하이브 리드 구조물이 성공적으로 형성되었음을 확인하였다. 이러 한 결과로 볼 때, 해당 기술을 바탕으로 다중 소재로 이루 어진 나노구조물의 하이브리드화가 가능하며, 향후 다양한 소재들의 조합에 의한 다중 나노구조물은 신기능 또는 고 성능의 차세대 에너지 및 전자소자에 적용이 가능할 것으 로 기대된다.

\section{감사의 글}

본 연구는 과학기술정보통신부의 이공학 개인기초연구지 원사업 (NRF-2017R1D1A1B03034490), 한국세라믹기술원 세라믹전략기술개발사업 (KPP17005), 과학기술정보통신부 의 한국연구재단-글로벌프론티어사업 (2013M3A6B1078874) (재)하이브리드 인터페이스기반 미래소재연구단의 지원을 받아 수행된 연구임.

\section{REFERENCES}

1. A. Debart, J. Bao, G. Armstrong, and P. G. Bruce, J. Power Sources 174, 1177 (2007).

2. M. Park, Y.-J. Jung, J. Kim, H. I. Lee, and J. Cho, Nano Lett. 13, 4833 (2013).

3. Z. Chen, A. Yu, D. Higgins, H. Li, H. Wang, and Z. Chen, Nano Lett. 12, 1946 (2012).

4. C. Liu, F. Li, L-P. Ma, and H.-M. Cheng, Adv. Mater. 22 , E28 (2010).

5. R. Raccichini, A. Varzi, S. Passerini, and B. Scrosati, Nature Mater. 14, 271 (2015).

6. T. Park, K. Kim, and O. Song, Korean J. Met. Mater. 55, 440 (2017).

7. M. Penza, C. Martucci, and G. Cassano, Sens. Actuators B 50, 52 (1998).

8. J. C. Kim, H. K. Jun, J.-S. Huh, and D. D. Lee, Sens. Actuators B 45, 271 (1997).

9. X. Chen and H. J. Schluesener, Toxicol. Lett. 176, 1 (2008).

10. S. Meesuk, J.-P. Cao, K. Sato, Y. Ogawa, and T. Takarada, Energy Fuels, 25, 4113 (2011).

11. Y.-G. Guo, J.-S. Hu, and L-J. Wan, Adv. Mater. 20, 2878 (2008).

12. G. Girishkumar, B. McCloskey, A. C. Luntz, S. Swanson, and W. Wilcke, J. phys. Chem. Lett. 1, 2193 (2010).

13. M.-K. Min, J. Cho, K. Cho, and H. Kim, Electrochim. Acta 45, 4211 (2000).

14. M. Lefevre, E. Proietti, F. Jaouen, and J.-P. Dodelet, Science 324, 71 (2014).

15. C. M. Pedrero, H. Silva, D. A. P. Tanaka, S. Liguori, A. Iulianelli, A. Basile, and A. Mendes, Appl. Catal. B: Environ. 174, 67 (2015).

16. C. Chen, Y. Kang, Z. Huo, Z. Zhu, W. Huang, H. L. Xin, J. D. Snyder, D. Li, J. A. Herron, M. Mavrikakis, M. Chi, K. L. More, Y. Li, N. M. Markovic, G. A. Somorjai, P. Yang, and V. R. Stamenkovic, Science 343, 1339 (2014).

17. S. Yi, B. Yang, and Z.-S. Zhang, Met. Mater. Int. 23, 603 (2017). 